\title{
ÉTICA DEL DOCENTE UNIVERSITARIO
}

\author{
ORNA SÁNCHEZ, Oswaldo ${ }^{308}$
}

SUMARIO: 1. Introducción. - 2. El surgimiento de los códigos de ética profesional. - 3 . La ética del docente universitario. - 4. Las tres dimensiones de la vida profesional. -5 . Los fines del docente universitario. -6 . Deberes y derechos. -7 . Derechos y deberes. -8 . La ética del profesional universitario. -9 . El profesional universitario. - 10. El sentido social de la profesión universitaria. - 11. Conclusiones.

\section{Introducción}

Aunque mucho se ha escrito sobre la deontología profesional, hay pocas reflexiones sobre las posibilidades de una Ética Profesional del docente universitario.

Por ello, el objetivo de nuestro trabajo es justificar la necesidad de un Código de Ética para los docentes universitarios, reflexión teórica que nos pueda permitir formular una propuesta del mencionado Código.

El objetivo es verificar que se han trastocado los valores éticos, jurídicos, políticos, la función de la universidad, la conducta del docente universitario, como consecuencia de la globalización en nuestra sociedad.

Consideramos oportuno nuestro trabajo porque frente a la crisis moral de las instituciones políticas y sociales de nuestro país, se requiere repensar en la formación y la responsabilidad de los profesionales en dichas instituciones. La universidad es el centro de

308 Abogado por la Universidad Nacional de San Marcos; profesor de Filosofía y Ciencias Sociales por la Universidad Federico Villarreal; Licenciado en Filosofía por la Universidad Nacional Mayor de San Marcos; Doctor en Ciencias de la Educación por la Universidad Nacional Enrique Guzmán y Valle, "La Cantuta"; Maestría en Derecho y Ciencia Política, con mención en Derecho Civil y Comercial de la Universidad Nacional Mayor de San Marcos.

Ha sido docente en la Universidad Nacional Enrique Guzmán y Valle, "La Cantuta". En la actualidad es profesor del Departamento Académico de Humanidades de la Universidad Ricardo Palma, en las asignaturas: Filosofía, Derecho y Lógica. Es autor del Texto y el Manual de Práctica de Sociología General, Manuales de Práctica de Filosofía, Fundamentos de Derecho y de Lógica. Ha publicado el Libro Ética y Deontología del Docente Universitario. Ha participado en diversos congresos y ha publicado artículos de su especialidad en diferentes revistas. 
formación de los profesionales, de lo que la crisis moral de nuestro país nos está diciendo que también está fallando la formación.

\section{El surgimiento de los códigos de ética profesional}

En la época moderna aparecen propiamente lo que hoy conocemos por profesiones, las cuales van requiriendo códigos para el buen desempeño de sus actividades. Los antecedentes son juramentos (como el de Hipócrates) y normas generales sin llegar a constituir códigos de ética.

Los códigos de ética profesional surgen entonces con la aparición de las profesiones modernas. Estas se van constituyendo en torno a instituciones o colegios profesionales. Los colegios profesionales tienen una doble finalidad, una interna y otra externa. La interna es garantizar una correcta práctica de la actividad profesional. La externa es impedir que personas inescrupulosas accedan a actividades para las cuales no han sido preparadas. Así, protegen el mercado laboral.

Es en ese contexto, los códigos de ética se hicieron necesarios para el ejercicio de las profesiones.

En nuestro país existen más de 30 colegios profesionales (según datos obtenidos del Consejo Nacional de Colegios Profesionales), con sus respectivos Estatutos y Códigos de Ética Profesional; siendo el primer Código de Ética Profesional el de Abogados del Perú, Ley de creación N. ${ }^{\circ}$ 31-07 de 1804, promulgada por el Gobierno de la Real Cédula de Madrid; y en el Gobierno Republicano, la Ley de Creación № 1367 del 20-12-1910 y el primer Código de Ética del 18-12-1950.

Además, hay algunas actividades profesionales que no tienen colegios ni códigos de ética. Es el caso de los literatos, filósofos, lingüístico, tal vez se debe a que estas actividades tienen poca importancia en el mercado laboral ni están sometidas al pensar científico-técnico.

\section{Diversas son las razones por las cuales es necesario un código de ética del docente universitario, como son las siguientes:}

1. Recientemente se ha creado el Colegio Profesional de los Profesores de Educación Primaria y Secundaria, Ley No 25231 y por medio del D.S. N. 001-2004-ED de fecha 1901-2004, se aprobó el Estatuto del mencionado Colegio Profesional.

2. La mayoría de profesiones tiene su colegio profesional, y por consiguiente, su Código de Ética Profesional.

3. Para ejercer la actividad docente en las universidades se necesita el título profesional que está mencionado en la Ley Universitaria y en los estatutos de las universidades.

4. Actividades como la función pública tienen su Código de Ética (Ley N 27815 del 13/08/ 2002).

5. El Congreso de la República tiene su Código de Ética (Resolución Legislativa No 0212002-CR). 
6. Proyecto de ley que establece la enseñanza obligatoria del curso de ética y moral en todos los niveles del sistema educativo del Perú, del 10 de enero de 2003, debido a la carencia de valores ético-morales en la mayoría de los peruanos: gobernantes y gobernados.

7. Las universidades son instituciones educativas del más alto nivel que forman a los diferentes profesionales y sus docentes tienen una gran responsabilidad en la formación de los futuros profesionales, por consiguiente, que van a prestar servicios en las diferentes necesidades de la sociedad y del Estado.

8. Asimismo, en el contexto nacional se muestra una crisis de valores en los sectores económicos, políticos, educativos, jurídicos, mostrándose sus consecuencias en la vida social del pueblo peruano. La corrupción política de la década pasada no ha sido pues un evento casual, sino que ha cuestionado a todas las instituciones sociales. Y no se puede ocultar que muchos profesionales han representado un triste papel en dicha corrupción y; en nuestros días, persiste la inmoralidad y la corrupción de nuestros gobernantes.

Por todas estas consideraciones, insistimos en la necesidad de un Código de Ética del docente universitario.

\section{3. Ética del docente universitario}

El esquema que vamos a seguir para teorizar la ética profesional del docente universitario es el que utiliza el comunitarismo (corriente ética y política que afirma la comunidad y su tradición como espacios en los que se da la vida buena: realización de la vida humana).

En dicho esquema se plantea la relación entre fines, normas y virtudes. Los fines son los ideales que orientan la actividad. Las normas nos ayudan a encaminarnos hacia ese fin, son como el mapa que nos lleva a donde queremos. Las virtudes son las disposiciones necesarias para emprender la caminata.

\section{Las tres dimensiones de la vida profesional}

Como todo profesional, el docente universitario en el ejercicio de su actividad está poniendo en juego tres dimensiones de la existencia: la dimensión social, la dimensión económica y la dimensión personal.

a) La dimensión social significa que su carrera satisface una necesidad social. que es la de participar en la formación de las nuevas generaciones y por ello permitir la continuidad de la cultura humana, sea a través de la conservación o de la renovación (vocación).

b) La dimensión económica se refiere a los resultados económicos de su actividad, es decir. el ejercicio de la profesión influye tanto en la economía de la sociedad como en la economía personal (la profesión es un medio de vida).

c) La dimensión personal. Toda profesión es una actividad humana social, esta dimensión significa - para nuestro caso- que la actividad docente afecta la vida personal del profesor. tanto externa como internamente.

d) El profesional educador no es una persona ética en algún momento de su actividad, sino que toda su actividad está sostenida por su compromiso ético (ética social, económica y personal). 


\section{Los fines del docente universitario}

En la educación existen fines o bienes intrínsecos y extrínsecos (Macintyre), que requieren de medios adecuados. Si dichas finalidades no se encuentran articuladas, el proceso educativo no encuentra plenitud. ¿Cuál es el fin último de la educación?, es participar en la realización de seres humanos, por lo que la labor universitaria tiene una finalidad humanizante.

Los documentos legales que sostienen el sistema universitario como la Ley Universitaria y los Estatutos de las Universidades ya nos señalan los fines de la actividad universitaria en general y de la actividad docente en particular.

Dentro de los fines de la universidad peruana, podemos mencionar (Art. $2^{\circ}$ de la Ley):

a) Conservar, acrecentar y transmitir la cultura universal con sentido crítico y creativo afirmando preferentemente los valores nacionales.

b) Realizar investigaciones en las humanidades, las ciencias y las tecnologías, y fomentar la creación intelectual y artística.

c) Formar humanistas, científicos y profesionales de alta calidad académica, de acuerdo con las necesidades del país.

Artículo $\mathbf{4 3}^{\circ}$. Es inherente a la docencia universitaria la investigación, la enseñanza, la capacitación permanente y la producción intelectual.

\section{Las virtudes del docente universitario}

La palabra "virtud" (gr. areté) nos recuerda las éticas griegas que buscaban la excelencia de la vida humana y de sus actividades. La virtud es el desarrollo perfecto, la excelencia de una cosa o acción, esta excelencia a su vez depende de la finalidad.

Aplicando estos términos a nuestro tema, diremos que la virtud de la educación es el desarrollo perfecto de la acción educativa. ¿Y cuándo alcanza su perfección? Cuando cumple su finalidad. Y cumple su finalidad cuando el acto es realizado plenamente, es decir, cuando estamos involucrados en la actividad de educar.

La virtud del docente consiste en la acción atenta y comprometida con la educación para construir una sociedad democrática y justa. Culturiza, porque la educación es la forma humana que tenemos que continuar, respetar y recrear la cultura humana, tanto a nivel de conocimientos como de formas de vida.

\section{Deberes y derechos}

La ética del educador tiene sentido si se tiene en cuenta tres aspectos: la sociedad, la ética y la educación, aspectos interrelacionados entre sí en la acción educativa misma, dentro del marco de los derechos fundamentales: reconocimiento económico, social, político, profesional, gremial y los deberes: dedicación, puntualidad, eficiencia, perfeccionamiento y vida ejemplar.

Veamos cómo se presentan los deberes de los profesores universitarios, en la Ley Universitaria: 
Artículo 51 ${ }^{\circ}$. Son deberes de los Profesores Universitarios:

a) El ejercicio de la cátedra con libertad de pensamiento y con respeto a la discrepancia;

b) Cumplir con el Estatuto de la Universidad y sus reglamentos y realizar cabalmente y bajo responsabilidad las actividades de su cargo;

c) Perfeccionar permanentemente sus conocimientos y capacidad docente y realizar labor intelectual creativa;

d) Observar conducta digna;

e) Presentar periódicamente informes .sobre el desarrollo de su labor en caso de recibir remuneración especial por investigación; y;

f) Ejercer sus funciones en la Universidad con independencia de toda actividad política partidaria.

\section{La ética del profesional universitario}

Se discute quién es responsable de la formación moral de las personas: hay quienes dicen que es la familia, la comunidad (iglesia) y, finalmente, responsabilizan a la escuela (en nuestro caso incluiríamos la universidad).

Las tres son necesarias e indispensables para mantener el equilibrio ético y profesional.

Los fines, normas y virtudes de la docencia dependen de cada actividad profesional, así como de sus instituciones y respectivos códigos.

\section{El profesional universitario}

Una de las objeciones para no aceptar un código de ética podría ser sostener que la docencia no es una profesión, pero esto es una equivocación por las consideraciones que pasamos a exponer.

Hortal, cuando dice que la docencia tiene todas las características que definen a una profesión, por las siguientes razones:

a) Presta un servicio específico a la sociedad;

b) Es una actividad encomendada y llevada a cabo por un conjunto de personas (los profesionales) que se dedican a ella de forma estable y obtienen de ella su medio de vida;

c) Los profesionales acceden a la docencia tras un largo proceso de capacitación, requisito indispensable para estar acreditados para ejercerla;

d) Los profesionales forman una entidad más o menos organizada (el cuerpo docente o el colegio profesional), que tiene o pretende obtener el control monopolístico sobre el ejercicio de su profesión.

Es responsabilidad de la Universidad la educación moral de los futuros y nuevos profesionales. La universidad es una colectividad integrada por una selección privilegiada de la intelectualidad de una sociedad, por su posición estratégica y funcional dentro y fuera del país, para relacionarse e interactuar con otras organizaciones sociales y tener a su alcance los medios y materiales para el desarrollo de la ciencia, la cultura y tecnología en la formalización y actualización permanente de los nuevos profesionales. 


\section{El sentido social de la profesión universitaria}

El rol y responsabilidad de todo profesional universitario para con la sociedad no se limita sólo a transmitir conocimientos, sino más bien, abarca el "establecimiento y defensa de los fundamentos intelectuales de la vida moral y el desarrollo del sentido de aquellas realidades que son espirituales por naturaleza, como la verdad y la belleza".

El docente universitario es el llamado a ser el más solidario de una colectividad, de esa solidaridad nace el prestigio, la dignidad personal o competencia moral que es la mejor garantía del éxito profesional, el cual radica en el escrupuloso cumplimiento del deber para el orden y el bien general de la sociedad en que vive. Por eso, como sostiene Cortina, la sociedad está legitimada para exigir a los profesionales (y a los docentes) a que realicen el bien interno de la actividad que desempeñan.

\section{Conclusiones}

1. Las universidades son instituciones educativas del más alto nivel, cuyos docentes son profesionales que deben respeto a sus respectivos códigos. Además la universidad es un espacio de confluencias con diferentes profesionales, todos tienen como misión la formación integral de los alumnos, así tienen una gran responsabilidad en la formación de los futuros profesionales que van a prestar servicios a la sociedad en general. Por todo ello, es imprescindible un Código de Ética Profesional del Docente Universitario explícito y no sólo intuitivo, para orientar las actividades del docente universitario.

2. Como todo profesional, el educador en el ejercicio de su actividad está poniendo en juego tres dimensiones de la existencia: la dimensión social, la dimensión económica y la dimensión personal. Si están presentes estos tres elementos, entonces podemos decir que realizamos nuestra actividad por amor, es decir, amamos lo que hacemos. Todo ejercicio profesional influye en la sociedad y a su vez la sociedad influye sobre la actividad profesional. Esa interinfluencia también se da en todos los niveles de la educación. Específicamente, la docencia es un medio de vida, por eso el profesor requiere de un sustento necesario para vivir dignamente. El trabajo profesional presta una importante contribución a la configuración de la identidad del que lo ejerce. El profesional educador no es una persona ética en algún momento de su actividad, sino que toda su actividad está sostenida por su compromiso ético.

3. También debemos interrogamos sobre el sentido de nuestra actividad. ¿Cuál es el fin, de la educación? Participar en la realización de seres humanos, por lo que la labor universitaria tiene una finalidad humanizante.

4. La Ley Universitaria y los Estatutos de las Universidades nos señalan los fines de la actividad universitaria en general y de la actividad docente en particular. Es inherente a la actividad universitaria la investigación, la enseñanza, la capacitación permanente y la producción intelectual. La investigación es el núcleo de la universidad, la cual permite la capacitación permanente o renovación de los conocimientos y, además, a elevar la calidad de la docencia. 
5. La vida universitaria está normada por la Constitución Política. la Ley Universitaria y por los Estatutos de cada Universidad, en los cuales se encuentran consignados los deberes y derechos de los miembros de la comunidad universitaria. Nuestra Carta Magna especifica la defensa de la persona humana y el respeto a su dignidad, son el fin supremo de la sociedad y el Estado.

6. Las normas del derecho son para cumplirlas, en caso contrario hay una sanción: las normas morales, en cambio, están abiertas a la libertad individual, a la razón y a la conciencia, pero siempre tienen consecuencias sociales. El derecho se impone al sujeto como una fuerza externa; en cambio, la norma moral se impone como una fuerza interna y autónoma, es consustancial a lo valioso. Aplicando a nuestro caso, la comunidad universitaria debería dictar sus propias normas morales, a partir de las cuales puede desempeñarse con libertad.

7.

8. Los docentes universitarios deben cumplir con las disposiciones legales vigentes: La Constitución Política, La Ley Universitaria, el Estatuto de la Universidad y demás disposiciones, para ejercer eficientemente su labor. Es contrario a la ética todo acto practicado por un docente universitario, cuya intención sea alterar las disposiciones de la Constitución Política, la Ley, el Estatuto y Reglamento, o impedir su cumplimiento en cada una o en todas sus partes.

9. La ética del educador tiene sentido si se tiene en cuenta tres aspectos: La sociedad, la ética y la educación, aspectos interrelacionados entre sí en la acción educativa misma. La formación moral del pueblo descansa en un trípode: la familia, la comunidad e institución educativa (escuela, colegio, universidad). En ellas sin amor no es posible educar; todos tenemos experiencia de esto, nos resistimos a ser educados por quien no nos quiere. No solamente es importante el ejemplo de vida, sino la acción y la orientación ideológica en la investigación y en el descubrimiento.

10. El rol y responsabilidad de todo profesional universitario para con la sociedad no se limita solo a trasmitir conocimientos, además abarca el establecimiento de los fundamentos intelectuales de la vida moral y el desarrollo del sentido de aquellas realidades que son espirituales por naturaleza, como la verdad y la belleza.

11. La moral se ha deteriorado en todos los niveles de la sociedad peruana, esa situación exige de sus profesores un rearme moral práctico: el establecimiento de pautas que rijan la conducta, inculque valores y vele sin descanso por la convivencia pacífica, la tolerancia, la responsabilidad, el amor al trabajo y a la patria. La moral es una constante en la vida del hombre, porque no se puede vivir sin normas ni valores. Por las consideraciones anteriores, creemos que es imprescindible la instauración de un código de ética profesional en todas las universidades.

12. La profesión universitaria no es neutra, es comprometida y relacionada con todos los sectores de la realidad: la ciencia, la cultura, la tecnología y sobre todo con la vida. La función de la profesión es pensar en la realidad, por ello es necesaria la constante actualización y capacitación. 
13. Más de treinta profesiones cuentan con sus Colegios Profesionales y sus respectivos Códigos de Ética Profesional, siendo el primero el de los Abogados.

\section{REFERENCIAS BIBLIOGRÁFICAS}

1. Abugattás, Juan. El problema de las necesidades y la ética. (tesis), UNMSM, Lima, 1976.

2. Aranguren, José Luis. Ética. Biblioteca Nueva. Madrid, 1997.

3. Aristóteles. bras Completas. Aguilar, Madrid, 1973.

4. Barroso Asenjo, Porfirio. Fundamentos Deontológicos de las Ciencias de la Información. Mitre. Barcelona, 1985.

5. Bunge, Mario. Ética y Ciencia. Siglo Veinte, Buenos Aires, 1986.

6. Cardona, Carlos. Ética del Quehacer Educativo. Rialp, Madrid. 1990.

7. Cortina A., Conil y Otros. Diez Palabras Clave en Ética de la Profesiones. Verbo Divino, Navarra, 2000.

8. Gómez Robledo, Antonio. Ensayo sobre las Virtudes Intelectuales. Fondo de Cultura Económica. México, 1996.

9. Hallet, Carlos. El Profesional y la Ética de Hoy. Imprenta Salesianos, Chile. 1997.

10. Macintyre, Alasdair. Historia de la Ética. Paidós, Barcelona, 1982.

11. MacIntyre, Alasdair. Tras la Virtud. Cátedra, Barcelona, 1987.

12. Méndez. Aquiles. Ética Profesional. Herrero Hermanos. México, 1965.

13. Polo Santillán, Miguel. Ética. Modo de Vida, Comunidad y Ecología. Mantaro. Lima, 2001.

14. Regal, Alberti. Fundamentos de la Ética Profesional. Publicaciones de la Universidad de Lima. Lima, 1994.

15. Suárez Villegas, Juan. Principios de Ética Profesional. Tecnos, Madrid, 2001. 